\title{
Pharmacological obstetric analgesia: a study of obstetric and neonatal outcomes
}

\author{
Analgesia obstétrica farmacológica: um estudo sobre os desfechos obstétricos e neonatais
}

Ruanna Lorna Vieira Fernandes ${ }^{1}$, Ana Kelve de Castro Damasceno ${ }^{1}$, Marta Maria Soares Herculano², Raquel de Serpa Torres Martins ${ }^{1}$, Mônica Oliveira Batista Oriá ${ }^{1}$

Objective: to investigate the association between pharmacological obstetric analgesia and obstetric and neonatal outcomes. Methods: it was a retrospective case-control study conducted with 393 pregnant women comprising 131 cases of pharmacological obstetric analgesia and 262 controls that did not perform this procedure. The sociodemographic and obstetric profile, the circumstances of parturient admission, obstetrical decisions, and obstetric and neonatal outcomes were investigated. Results: pregnant women submitted to pharmacological analgesia during labor presented an increased risk for the use of exogenous oxytocin $(p<0.001)$, episiotomy $(p=0.001)$, Kristeller maneuver ( $p=0.036)$, and forceps $(p=0.004)$. Conclusion: pharmacological analgesia does not increase the risk of spontaneous perineal tear, abdominal delivery, and hospitalization in neonatal unit. Nevertheless, it influences the increased risk of synthetic oxytocin use, Kristeller maneuver, episiotomy, forceps, and the occurrence of lower first-minute Apgar scores.

Descriptors: Analgesia, Obstetrical; Humanizing Delivery; Labor Pain; Obstetric Nursing.

Objetivo: investigar a associação entre a analgesia obstétrica farmacológica e os desfechos obstétricos e neonatais. Métodos: estudo retrospectivo do tipo caso-controle, com 393 parturientes, sendo 131 casos que realizaram analgesia obstétrica farmacológica e 262 controles que não realizaram. Foram investigados o perfil sociodemográfico e obstétrico, as circunstâncias da admissão da parturiente, as condutas obstétricas e os desfechos obstétricos e neonatais. Resultados: parturientes submetidas à analgesia farmacológica durante o trabalho de parto apresentaram risco aumentado para o uso de ocitocina exógena $(p<0,001)$, episiotomia $(p=0,001)$, manobra de Kristeller $(p=0,036)$ e fórceps $(p=0,004)$. Conclusão: a analgesia farmacológica não aumenta o risco de laceração perineal espontânea, parto abdominal e internação em unidade neonatal, contudo influencia no aumento do risco de uso de ocitocina sintética, realização de Manobra de Kristeller, episiotomia, fórceps e ocorrência de escores menores de APGAR no $1^{\circ}$ minuto.

Descritores: Analgesia Obstétrica; Parto Humanizado; Dor do Parto; Enfermagem Obstétrica.

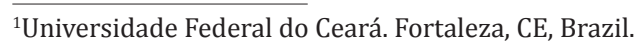

${ }^{2}$ Centro Universitário Christus. Fortaleza, CE, Brazil.

Corresponding author: Ruanna Lorna Vieira Fernandes

Rua Olegário Memória, 3838. CEP: 60833045. Fortaleza, CE, Brazil. E-mail: ruannavieira@hotmail.com
} 


\section{Introduction}

Humanized obstetric nursing care should be conducted with sensitivity, respect, and dignity to the mother-child binomial, creating a welcoming atmosphere with professional and institutional attitudes that break with the traditional model of impersonality and violence imposed on pregnant women. Humanizing childbirth means respecting and creating favorable conditions for the whole - spiritual, psychological, and biological aspects of the human beings involved through procedures that have proven to be beneficial to the mother-child binomial, avoiding unnecessary interventions and establishing relationships based on ethical principles ${ }^{(1-2)}$.

Obstetric humanization is structured around three essential pillars: the autonomy of women, the care conducted by a multiprofessional team, and the assistance based on scientific evidence. Following this model, it is worth highlighting that all the interventions to be performed in pregnant women should be previously clarified and consented by them so that there is in fact the humanized assistance at bir$\mathrm{th}^{(3)}$. The fear of pain, which is cultural in Brazil, has contributed greatly to the high rates of unnecessary cesarean sections in the country. According to the National Guidelines on Care in Normal Birth, health professionals should reflect on how their own beliefs and values can influence their attitudes in dealing with the pain of childbirth. In this context, professionals, including obstetric nurses, are responsible for guiding, enabling the access, and supporting women regarding the decision on using non-pharmacological and/or pharmacological analgesia during labor ${ }^{(4)}$.

Obstetric analgesia is understood as the suppression of the physical pain demanded especially by the uterine contraction and cervical dilation. This analgesia can be obtained through non-pharmacological procedures (massages, immersion in warm water, music therapy, aromatherapy, and acupuncture); administration of drugs with systemic action (inhalation, intramuscular, and intravenous); and local phar- macological analgesia (spinal, epidural, or combined spinal-epidural ${ }^{(4-5)}$. According to the Ministry of Health, all possibilities must be explained to the pregnant woman in the prenatal period and the non-pharmacological methods available should be offered before starting pharmacological analgesia( ${ }^{(4)}$.

Epidural analgesia is the gold standard in pharmacological analgesic practices during labor, which allows free maternal movement and has minimal side effects for the mother and fetus ${ }^{(4-8)}$. Inappropriate doses or techniques of pharmacological analgesia may expose the mother-child binomial to iatrogeneses, side effects, and mild to severe adverse reactions ${ }^{(3)}$. To improve the analgesic procedure in pregnant women, it is important to investigate the association between the use of pharmacological obstetric analgesia and obstetric and neonatal outcomes. Experimental studies have been carried out internationally to consolidate techniques and safe analgesic dosages for the mother and fetus ${ }^{(9-10)}$.

Although this intervention has already been carried out in Brazil for over two decades, it was only incorporated into the public network of Ceará since 2011 and it was restricted to a maternity school, in sporadic shifts. To date, there are no other published studies approaching this issue in the State of Ceará. Therefore, this study aimed to investigate the association between pharmacological obstetric analgesia and obstetric and neonatal outcomes.

\section{Methods}

It was a retrospective case-control study with nested sampling. The universe of the study comprised the delivery room of a high complexity maternity school in Fortaleza, Ceará, Brazil, which registered 3,801 deliveries in 2013 , of which $48.8 \%$ were vaginal delivery ${ }^{(11)}$.

To select the sample of the Case Group, the register book for patients who used pharmacological obstetric analgesia was consulted; all the women who performed this procedure from January to December 
2013 were included in this group. To define the Control Group, the register books of admission of patients in the delivery room were consulted, being considered as inclusion criteria the initial diagnosis of labor, rupture of membranes, or preterm labor, without previous indication of cesarean section and those who did not perform pharmacological analgesia during labor.

In the literature review on pharmacological obstetric analgesia, the ideal ratio of controls per case was not identified, it was then decided to select, for each case patient, two control patients that were admitted preferentially on the days and at the approximate times when the cases were admitted into the delivery room. This pairing aimed to reduce possible biases in the differences in the obstetrical decisions among the on-call staff. The cases/controls that had no record on the type of delivery and/or first- and fifth-minute Apgar scores were excluded from the study.

Of the 135 case patients of pharmacological obstetric analgesia, four were excluded due to the lack of registration of the type of delivery, and one due to lack of registration of the Apgar score. For this reason, the Case Group consisted of 131 subjects. When selecting the Control Group by nested sampling, 262 pregnant women not exposed to pharmacological analgesia were included.

Data collection took place from August 2014 to July 2015, through the survey of the records of the Indicators of Care in Delivery and Birth. These indicators are registered in records standardized by the institution and used to monitor care based on good practices of assistance to the mother-child binomial. They are currently used as reference for the contracting process of maternity units in the "Cegonha" Network $^{(12)}$. Each parturient has a chart of the indicators in her file and, in the institution where this study took place, the obstetric nurse fills out this form.

The researcher analyzed the 393 records of the Indicators of Care in Delivery and Birth (131 cases and 262 controls), recording the data in a table of Microsoft Excel 2010. The variables registered were: sociodemographic profile (age, place of origin, and education), obstetric profile and circumstances at the time of admission (parity, initial diagnosis); obstetrical decisions (use of non-invasive methods for pain relief, oxytocin, episiotomy, and Kristeller maneuver), obstetric outcomes (type of delivery and presence of perineal tear), and neonatal outcomes (Apgar score and admission to neonatal unit).

Statistical analysis of the data was performed using the Statistical Package for the Social Sciences (version 20.0 for Windows), a statistical analysis software widely used in scientific studies. In this study, statistical crossings were performed to investigate the Odds Ratio (OR) between the performance of pharmacological obstetric analgesia and obstetrical decisions, and obstetric and neonatal outcomes. The results were organized and presented in tables.

The study complied with the formal requirements of national and international standards for research involving human beings.

\section{Results}

The age of the case patients ranged from 13 to 39 years, with a mean (M) of 23.2 years and Standard Deviation (SD) of \pm 6.5 years; and, in the control group, it ranged from 13 to 42 years, mean of 24.1 years ( $\mathrm{SD}= \pm 6.1$ years). Regarding the place of origin, 108 (82.4\%) women were from Fortaleza and 21 (16.0\%) from the interior of the state in the case group ( $n=129)$; while in the control group, 229 (87.4\%) lived in the capital and $31(11.8 \%)$ lived in the interior $(n=260)$.

Regarding the educational level, the instrument used by the institution did not allow the classification by years of study, but it was noticed that most of the sample $(89.6 \%)$ had only elementary or high school education. In the case group, 4 (3.0\%) women were only literate; $42(37.0 \%)$ studied until elementary school; 63 (54.0\%) studied in high school; and 7 $(6.0 \%)$ in higher education. In the control group, 2 (1.0\%) women were illiterate; 10 (4.0\%) participants were only literate; 111 (46.0\%) finished their studies in elementary school; 102 (42.0\%) interrupted high 
school; and 14 (7.0\%) started higher education.

In both groups, parity ranged from nulliparous to multiparous, but the percentage of nulliparas was higher in the case group (65.6\%) than in the control group (44.6\%). Table 1 presents the comparison regarding parity, admission diagnosis in the delivery room, and non-pharmacological methods of pain relief applied. Gestational age ranged from 32 weeks and five days to 42 weeks in the case group ( $M=39$ weeks). In the control group, the variation was from 32 weeks to 41 weeks and two days (M=38 weeks and six days). In both groups, cervical dilation at admission ranged from 0 to $10 \mathrm{~cm}$, with a mean of $5.13 \mathrm{~cm}$ in the case group $(\mathrm{SD}=1.8 \mathrm{~cm})$ and $5.71 \mathrm{~cm}$ in the control group (SD=2.5 cm).

Table 1 - Parity distribution, diagnosis at admission, and non-pharmacological methods of pain relief in the case and control groups

\begin{tabular}{lcc}
\hline \multirow{2}{*}{ Characteristics } & \multicolumn{2}{c}{ Case group Control group } \\
\cline { 2 - 3 } Parity & $\mathbf{n}(\%)$ \\
Nulliparous & $86(65.6)$ & $117(44.6)$ \\
1 or 2 deliveries & $41(31.3)$ & $126(48.1)$ \\
$\geq 3$ deliveries & $4(3.1)$ & $19(7.3)$ \\
Diagnosis at admission & & \\
Labor & $107(81.7)$ & $232(88.5)$ \\
Aminorexes & $12(9.2)$ & $15(5.7)$ \\
Premature labor & $9(6.9)$ & $16(6.1)$ \\
Others* & $14(10.8)$ & $12(4.6)$ \\
Non-pharmacological methods of pain relief & \\
Obstetric swing chair & $70(53.4)$ & $78(29.8)$ \\
Shower & $60(45.8)$ & $77(29.4)$ \\
Exercise & $35(26.7)$ & $39(14.9)$ \\
Massage & $33(25.2)$ & $43(16.4)$ \\
Bobath ball & $19(14.5)$ & $17(6.5)$ \\
Fixed bar & $6(4.6)$ & $11(4.1)$ \\
Ling scale & $2(1.5)$ & $6(2.3)$ \\
Music therapy & - & $3(1.1)$ \\
Shiatsu & - & $1(0.4)$ \\
Reflexology & - & $1(0.4)$ \\
Not specified & $1(0.8)$ & $22(8.4)$ \\
Not registered & $31(23.7)$ & $120(45.9)$ \\
\hline bother: Cervical isthmus insufficiency, syphilis, hypertensive syndrome, dia- \\
pothyroidism, and previous cesarean section \\
\end{tabular}

Of the 131 records of the case group, only 60 presented record of the patient's cervical dilation at the beginning of pharmacological obstetric analgesia. This parameter ranged from 3 to $10 \mathrm{~cm}(\mathrm{M}=6.4$, $\mathrm{SD}= \pm 1.6$ ). There was no record of the technique and anesthetic dosage applied.

Table 2 shows the comparison between case and control groups regarding obstetrical decisions and obstetric outcomes: use of synthetic oxytocin, episiotomy and Kristeller maneuver, type of delivery, and presence of perineal tear. The sample varied according to the presence of registration of the topics in question in the record of indicators evaluated.

Table 2 - Distribution of obstetrical decisions and obstetric outcomes in the case and control groups

\begin{tabular}{|c|c|c|c|c|}
\hline \multirow{2}{*}{ Characteristics } & \multirow{2}{*}{$\begin{array}{c}\text { Case group } \\
\mathbf{n}(\%)\end{array}$} & \multirow{2}{*}{$\frac{\text { Control group }}{\text { n }(\%)}$} & \multirow{2}{*}{$\begin{array}{l}\text { Odds } \\
\text { ratio }\end{array}$} & \multirow{2}{*}{$\mathbf{p}$} \\
\hline & & & & \\
\hline \multicolumn{5}{|l|}{ Synthetic oxytocin } \\
\hline No & $32(28.3)$ & $171(68.7)$ & & \\
\hline Yes & $81(71.7)$ & $78(31.3)$ & 5.549 & $<0.001$ \\
\hline \multicolumn{5}{|l|}{ Kristeller maneuver } \\
\hline No & $102(93.6)$ & $255(98.1)$ & & \\
\hline Yes & $7(6.4)$ & $5(1.9)$ & 3.500 & 0.036 \\
\hline \multicolumn{5}{|l|}{ Episiotomy } \\
\hline No & $80(76.2)$ & $196(90.3)$ & & \\
\hline Yes & $25(23.8)$ & $21(9.7)$ & 2.916 & 0.001 \\
\hline \multicolumn{5}{|l|}{ Type of delivery } \\
\hline Vaginal & $96(73.3)$ & $218(83.2)$ & & \\
\hline Forceps & $13(9.9)$ & - & 61.134 & 0.004 \\
\hline Cesarean & $22(16.8)$ & $44(16.8)$ & 1.135 & 0.660 \\
\hline \multicolumn{5}{|l|}{ Perineal tear } \\
\hline No & $46(47.4)$ & $108(51.0)$ & & \\
\hline $1^{\text {st }}$ and $2^{\text {nd }}$ degrees & $48(49.5)$ & $100(47.1)$ & & \\
\hline $3^{\text {rd }}$ and $4^{\text {th }}$ degrees & $3(3.1)$ & $4(1.9)$ & 1.659 & 0.513 \\
\hline
\end{tabular}

There was a significant increase in the use of exogenous oxytocin (OR=5.549; $\mathrm{CI}=3.402-9.049$; $\mathrm{p}<0.001$ ) in the case group compared to the control group. Kristeller maneuver was also more present in the group that received pharmacological obstetric analgesia (OR=3.500; $\mathrm{CI}=1.085-11.281 ; \mathrm{p}=0.036$ ). An increase in episiotomy was identified (OR=2.916; $\mathrm{CI}=1.544-5.508 ; \mathrm{p}=0.001$ ). There was no significant difference in the incidence of spontaneous perineal 
tears, including extensive lacerations of perineum, sphincter, and rectum (OR=1.659; $\mathrm{CI}=0.364-7.562$; $\mathrm{p}=0.513$ ).

In this study, there was no difference in the percentage of cesarean sections when comparing the control and case groups (both at $16.8 \%$ of total deliveries; $\mathrm{OR}=1.135 ; \mathrm{CI}=0.645-1.998 ; \mathrm{p}=0.660$ ). Nonetheless, in 2013, 13 vaginal deliveries with forceps were registered in the institution's annual report, and the women underwent pharmacological obstetric analgesia (OR=61.134; $\mathrm{CI}=3.597-1038.933 ; \mathrm{p}=0.004)$.

Regarding neonatal outcomes, the first-minute Apgar score ranged from 2 to 10 in the control group ( $M=8.1)$, while in the case group, this index ranged from 0 to $9(M=7.7)$. At the fifth minute after birth, these scores ranged from 6 to 10 in the control group $(M=9.0)$, and from 0 to 10 in the case group ( $M=8.7)$. The only register of Apgar 0 at first and fifth minute after birth, in the case group, was a fetus that already had a death diagnosis during hospital admission. No death was recorded in the control group.

As for the outcome of hospitalization in neonatal unit, the two groups were very homogeneous, as described in Table 3, which also reveals the comparison between case and control groups for first- and fifth-minute Apgar scores.

Table 3 - Distribution of first- and fifth-minute Apgar scores and admission to neonatal unit in the case and control groups

\begin{tabular}{lcccc}
\hline Characteristic & Case group Control group $\begin{array}{c}\text { Odds } \\
\text { ratio }\end{array}$ & $\mathbf{p}$ \\
\hline First-minute Apgar score & & & & \\
7 to 10 & $113(86.3)$ & $250(95.4)$ & & \\
0 to 6 & $18(13.7)$ & $12(4.6)$ & 3.318 & 0.002 \\
Fifth-minute Apgar score & & & & \\
7 to 10 & $129(98.4)$ & $261(99.6)$ & & \\
0 to 6 & $2(1.6)$ & $1(0.4)$ & 4.046 & 0.256 \\
Newborn destination & & & & \\
Rooming-in unit & $97(77.0)$ & $206(80.0)$ & & \\
Unit I (Low risk) & $19(15.0)$ & $34(13.1)$ & & \\
Unit II (Medium risk) & $3(2.4)$ & $4(1.6)$ & \\
Intensive care unit & $6(4.8)$ & $14(5.3)$ & 1.184 & 0.519 \\
Death & $1(0.8)$ & - & \\
\hline
\end{tabular}

Data presented did not show an association between carrying out pharmacological obstetric analgesia and the increased indication of cesarean section due to altered fetal well-being or arrest disorders. However, an interesting fact is that babies born to women who underwent pharmacological analgesia were three times more likely to have first-minute Apgar scores <7 (OR=3.318; $\mathrm{CI}=1.546-7.120 ; \mathrm{p}=0.002$ ). Nonetheless, there was no significant difference between the two groups in the fifth-minute Apgar score (OR=4.046; $\mathrm{CI}=0.363-45.042 ; \mathrm{p}=0.256$ ). There was also no increased risk of newborn hospitalization in high-risk neonatal units when using pharmacological obstetric analgesia (OR=1.184; $\mathrm{CI}=0.708-1.981$; $\mathrm{p}=0.519$ ).

\section{Discussion}

Given the retrospective and documentary nature of this study, it was not possible to identify the technique, the dosage, and the drug used to perform analgesia. These variables have been essential to identify their possible benefits and complications ${ }^{(5-10,13)}$.

It was observed that the educational level in the case group was higher, in which $60.0 \%$ of pregnant women had at least high school education, while in the control group, the percentage of women with the same educational level was $49.0 \%$. International study conducted with 1,511 women attended by midwives in urban and rural areas verified that women with a higher educational level are also more likely to use pharmacological analgesia during labor. Furthermore, nulliparous women are more likely to require pharmacological analgesia than multiparous ones ${ }^{(14)}$. This finding corroborates this study, in which $65.6 \%$ of the cases were nulliparous, whereas only $44.6 \%$ of the control group were in their first parturition experience.

Study that followed the information process about pharmacological obstetric analgesia during prenatal care, the decision on availability or non-availability during labor, and the request/use of the resource 
identified that only $15.9 \%$ of the women reported, during prenatal care, to prefer pharmacological methods for pain relief. It also identified that only $74.7 \%$ of them did not request the use of analgesic drugs during labor, even in institutions that offered the resource ${ }^{(14)}$. This data is supported by the Ministry of Health, which recommends encouraging continuous support and implementation of all non-pharmacological methods available before starting pharmacological analgesia ${ }^{(4)}$.

This study identified that, in almost half $(45.9 \%)$ of the indicators belonging to the control group, there was no record of the use of non-pharmacological methods for pain relief, and in the case group, this rate fell to $23.7 \%$. This finding suggests that women who underwent pharmacological obstetric analgesia received greater support and attention from the on-call staff, either through the encouragement to adopt vertical positions, coziness of the environment, or implementation of non-pharmacological measures to relieve physical pain.

Pharmacological obstetric analgesia was considered a risk factor for Kristeller maneuver, since women in the case group were three times more likely to undergo the maneuver than pregnant women in the control group. In the light of current international literature, no comparative studies on the association between pharmacological obstetric analgesia and Kristeller maneuver were found, probably because this intervention was recognized as potentially damaging to the mother-child binomial ${ }^{(4)}$.

Retrospective study with 13,000 women undergoing pharmacological obstetric analgesia verified that early onset (cervical dilation less than $3 \mathrm{~cm}$ ) of analgesic drug use was associated with an increased need for interventions such as synthetic oxytocin, ruptured membranes, and instrumental delivery, including abdominal delivery ${ }^{(15)}$. Systematic review analyzed nine randomized clinical trials, totaling 15,752 participants, and demonstrated that there is no increased risk of instrumental or cesarean delivery in women receiving early epidural analgesia compared to those receiving late epidural analgesia ${ }^{(16)}$.

In this study, it was not possible to investigate whether analgesia was performed early or late, but it was observed that women submitted to pharmacological obstetric analgesia were more likely to require exogenous oxytocin and/or episiotomy. It was also emphasized the notorious increase in the need for using forceps in vaginal deliveries of women submitted to pharmacological obstetric analgesia. There was no significance in the correlation between pharmacological obstetric analgesia and the indication of cesarean section or the occurrence of spontaneous perineal tear of any degree.

It was verified the higher probability of first-minute Apgar score $<7$, but there was no significant difference in the fifth minute. This finding corroborates the literature, which confirms that pharmacological obstetric analgesia does not imply an increased risk for neonatal scores lower than 7 in the fifth minute of life $\mathrm{e}^{(9,16-17)}$.

It is an important nursing role to inform pregnant women about their right to pharmacological obstetric analgesia, the benefits and possible complications of this intervention, so that women can make an informed decision during labor as to whether they wish to use this resource. Obstetric nurses should provide continuous support to pregnant women, applying non-pharmacological methods as primordial technologies for pain relief, aiming to postpone the need for pharmacological analgesia as much as possible, since there is an increased risk for other obstetric interventions, like synthetic oxytocin, episiotomy, Kristeller maneuver, and instrumental vaginal delivery.

This study provides a first look, considering the current international literature, to the analgesic pharmacological practices in pregnant women in the public network of Ceará. Therefore, it is suggested the conduction of further prospective researches, with their own instrument, aiming to reduce sample losses and provide a better understanding of the techniques, drugs, and dosages used, including possible side effects and adverse events, aiming at greater safety of the offered procedure and high levels of maternal satisfaction. 


\section{Conclusion}

Pharmacological analgesia does not increase the risk of spontaneous perineal tear, abdominal delivery, and hospitalization in neonatal unit. Nonetheless, it influences the increased risk of synthetic oxytocin use, Kristeller maneuver, episiotomy, forceps, and the occurrence of lower first-minute Apgar scores.

\section{Collaborations}

Fernandes RLV and Oriá MOB contributed with the conception and design, data analysis and interpretation, drafting of the article, and final approval of the version to be published. Herculano MMS and Damasceno AKC contributed with the conception and design and critical review of relevant intellectual content. Martins RST contributed with the final approval of the version to be published.

\section{References}

1. Versiani CC, Barbieri M, Gabrielloni MC, Fustinoni SM. The meaning of humanized childbirth for pregnant women. J Res Fundam Care Online. 2015; 7(1):1927-35. doi: http://dx.doi.org/ 10.9789/2175-5361.2015.v7i1.1927-1935

2. Fujita JALM, Shimo AKK. Parto humanizado: experiências no sistema único de saúde. Rev Min Enferm. 2014; 18(4):1006-10. doi: http://www. dx.doi.org/10.5935/1415-2762.20140074

3. Leal MC, Pereira APE, Domingues RMSM, Theme Filha MM, Dias MAB, Pereira MN, et al. Obstetric interventions during labor and childbirth in Brazilian low-risk women. Cad Saúde Pública. 2014; 30(Sup):17-47. doi: http://dx.doi. org/10.1590/0102-311X00151513

4. Ministério da Saúde (BR). Secretaria de Ciência, Tecnologia e Insumos Estratégicos, Departamento de Gestão e Incorporação de Tecnologias em Saúde. Diretrizes Nacionais de Assistência ao Parto Normal: versão resumida [Internet]. 2017 [citado 2017s 28]. Disponível em: http://conitec. gov.br/images/Protocolos/Diretrizes/Diretrizes_ PartoNormal_VersaoReduzida_FINAL.pdf
5. Pereira LDP. Primórdios da analgesia de parto: a força das mulheres. Sci Med. 2014; 24(4):4204.doi:http://dx.doi.org/10.15448/19806108.2014.4.18161

6. Kranke P, Girard T, Lavand'Homme P, Melber A, Jokinen J, Muellenbach RM, et al. Must we press on until a young mother dies? Remifentanil patient controlled analgesia in labour may not be suited as a "poor man's epidural". BMC Pregnancy Childbirth. 2013; 13:139. doi: http://dx.doi. org/10.1186/1471-2393-13-139

7. Freeman LM, Bloemenkamp KW, Franssen MT, Papatsonis DN, Hajenius PJ, Van Huizen ME, et al. Remifentanil patient controlled analgesia versus epidural analgesia in labour. A multicentre randomized controlled trial. BMC Pregnancy Childbirth. 2012; 12:63. doi: http://dx.doi. org/10.1186/1471-2393-12-63

8. Nunes J, Nunes S, Veiga M, Cortez M, Seifert I. Estudo prospectivo, randômico, controlado e de avaliação cega do desfecho - infusão peridural contínua versus bolus epidural intermitente programado em analgesia de parto. Rev Bras Anestesiol. 2016; 66(5):439-44. doi: http:// dx.doi.org/10.1016/j.bjan.2015.10.003

9. Dostbil A, Celik M, Alici HA, Erdem AF, Aksoy M, Ahiskalioglu A. Maternal and neonatal effects of adding morphine to low-dose bupivacaine for epidural labor analgesia. Niger J Clin Pract. 2014; 17(2):205-11. doi: http://dx.doi. org/10.4103/1119-3077.127559

10. Stourac $P$, Suchomelova H, Stodulkova M, Huser M, Krikava I, Janku P, et al. Comparison of parturient controlled remifentanil with epidural bupivacain and sufentanil for labour analgesia: Randomised controlled trial. Biomed Pap Med Fac Univ Palacky Olomouc Czech Repub. 2014; 158(2):227-32. doi: http://dx.doi.org/10.5507/bp.2012.073

11. Maternidade Escola Assis Chateaubriand. Universidade Federal do Ceará, Complexo Hospitalar. Produção assistencial - ano 2013 [Internet]. 2013 [citado 2013 ago 18]. Disponível em: http://www. meac.ufc.br/arquivos/biblioteca_cientifica/File/ RELATORIOS\%20DE\%20GESTAO\%20E\%20INDICADORES/relatorioanualcorrigido2013 
12. Ministério da Saúde (BR). Cadernos HumanizaSUS: humanização do parto e do nascimento [Internet]. 2014 [citado 28 Set 2017]. Disponível em: http:// www.redehumanizasus.net/sites/default/files/ caderno_humanizasus_v4_humanizacao_parto. pdf

13. Jung H, Kwak KH. Neuraxial analgesia: a review of its effects on the outcomeand duration of labor. Korean J Anesthesiol. 2013; 65(5):379-84. doi: http://dx.doi.org/10.4097/kjae.2013.65.5.379

14. Klomp T, Jonge A, Hutton EK, Lagro-Janssen ALM. Dutch women in midwife-led care at the onset of labour: which pain relief do they prefer and what do they use? BMC Pregnancy Childbirth. 2013; 13:230. doi: http://dx.doi.org/10.1186/14712393-13-230
15. Moore AR, Shan WLP, Hatzakorzian R. Predicting early epidurals: association of maternal, labor, and neonatal characteristics with epidural analgesia initiation at a cervical dilation of $3 \mathrm{~cm}$ or less. Local Reg Anesth. 2013; 6:25-9. doi: http://dx.doi. org/10.2147/LRA.S46686

16. Sng B, Leong W, Zeng Y, Siddiqui F, Assam PN, Lim Y, et al. Early versus late initiation of epidural analgesia for labour. Cochrane Database Sys Rev. 2014; 10. doi: http://dx.doi.org/10.1002/14651858.CD007238. pub2

17. Amaral HRM, Sarmento Filho EDS, Silva DM, Barbosa TLA, Gomes LMX. Repercussões maternas e fetais da analgesia obstétrica: uma revisão integrativa. Av Enf. 2015; 33(2):282-94. doi: http:// dx.doi.org/10.15446/av.enferm.v33n2.52176 